\title{
MINIMIZACIÓN DE RESIDUOS DE CROMO MEDIANTE LA APLICACIÓN DE UNA TÉCNICA DE RECICLADO DIRECTO DE LICORES DE PIQUELADO - CURTIDO EN EL PROCESAMIENTO DE PIELES
}

\author{
Ramiro Escalera Vásquez, Luis Arteaga Weill y Rodrigo Vega M.
}

\section{RESUMEN}

Uno de los problemas ambientales confrontados por las curtiembres bolivianas es la emisión de residuos líquidos contaminados con cromo, del cual se desechan significativas cantidades en los procesos convencionales. Aunque este versátil metal pesado juega un rol importante en el metabolismo de plantas y animales, en bajas concentraciones, sus derivados oxidados, $\mathrm{Cr}$ (VI), son extremadamente tóxicos. Como alternativa de prevención de la contaminación, se ha realizado una investigación en torno a la aplicación del método de Reciclado Directo de Licores Residuales en la etapa de piquelado - curtido de pieles. Se ha demostrado mediante numerosas corridas experimentales realizadas en laboratorio y en planta, que el reciclaje directo de licores residuales de curtido es técnicamente viable para su implantación en las etapas de piquelado y curtido del proceso de fabricación de cueros al cromo en una curtiembre común. La calidad del cuero terminado no se deteriora con el re-uso directo de los licores de cromo hasta en 10 reciclos. El control del proceso puede realizarse con la medición de parámetros muy simples: La densidad de los licores, la fuerza iónica relacionada con la densidad, el grado de acidez ( $\mathrm{pH}$ ) y la concentración de cromo en los licores residuales. Se generan ahorros importantes en el consumo de reactivos químicos, entre el $9 \%$ y el $44 \%$, y sobre todo, en consumo de agua, $77 \%$. La mitigación del impacto ambiental producido por el contenido de $\mathrm{Cr}(\mathrm{III})$ en los licores de curtido, se traduce en una disminución de más de $70 \%$ de la masa desechada de $\mathrm{Cr}(\mathrm{III})$, cuando se usa el reciclado directo, respecto de la masa que se desecha en curtidos normales sin reciclo. La implementación del reciclado directo de licores de cromo es replicable a otras industrias similares, que existen en gran número en Bolivia.

Palabras Clave: Recuperación de Cr (III), Piquelado-Curtido al Cromo, Reciclado Directo, Licores de Cromo. 